Wright State University

CORE Scholar

Pharmacology and Toxicology Faculty

Publications

Pharmacology and Toxicology

2014

\title{
Anti-cancer Effects of Glypican-3 on Huh-7 Hepatocellular Carcinoma Cells
}

Jiyu Wen

Xiaojun Wen

Jinju Wang

Wright State University - Main Campus, wang.140@wright.edu

Yang Shu

Zhidong Qiu

See next page for additional authors

Follow this and additional works at: https://corescholar.libraries.wright.edu/ptox

Part of the Chemicals and Drugs Commons

\section{Repository Citation}

Wen, J., Wen, X., Wang, J., Shu, Y., Qiu, Z., Liu, Z., Li, R., Zeng, G., Bao, S., Miao, H., Chen, Y., \& Li, M. (2014). Anti-cancer Effects of Glypican-3 on Huh-7 Hepatocellular Carcinoma Cells. Journal of Cell Science \& Therapy, 5(5), 186.

https://corescholar.libraries.wright.edu/ptox/74

This Article is brought to you for free and open access by the Pharmacology and Toxicology at CORE Scholar. It has been accepted for inclusion in Pharmacology and Toxicology Faculty Publications by an authorized administrator of CORE Scholar. For more information, please contact library-corescholar@wright.edu. 


\section{Authors}

Jiyu Wen, Xiaojun Wen, Jinju Wang, Yang Shu, Zhidong Qiu, Zhongkao Liu, Ran Li, Guofang Zeng, Shiting Bao, Huilai Miao, Yanfang Chen, and Mingyi Li 


\section{Anti-cancer Effects of Glypican-3 on Huh-7 Hepatocellular Carcinoma Cells}

Jiyu Wen ${ }^{1 \#}$, Xiaojun Wen ${ }^{2 \#}$, Jinju Wang ${ }^{3}$, Yang Shu ${ }^{2}$, Zhidong Qiu $^{2}$, Zhongkao Liu ${ }^{2}$, Ran Li $^{2}$, Guofang Zeng ${ }^{2}$, Shiting Bao ${ }^{2}$, Huilai Miao $^{2}$, Yanfang Chen $^{2,3^{*}}$ and Mingyi Li ${ }^{*}$

${ }^{1}$ Department of Oncology, Affiliated Hospital of Guangdong Medical College, Zhanjiang, Guangdong, China

${ }^{2}$ Department of Hepatobiliary Surgery, Affiliated Hospital of Guangdong Medical College, Zhanjiang, Guangdong, China

${ }^{3}$ Department of Pharmacology and Toxicology, Wright State University Boonshoft School of Medicine, Dayton, OH, USA

\#Equally Contributed

*Corresponding authors: Yanfang Chen, Department of Pharmacology and Toxicology, Wright State University Boonshoft School of Medicine, Dayton, OH, USA, 45435, Tel: 937-775-3265; Fax: 937-775-7221; E-mail: yanfang.chen@wright.edu

Ming-Yi Li, Affiliated Hospital of Guangdong Medical College, Zhanjiang, Guangdong, P.R China, 52400, Tel: 86-759-238-7417; Fax: 86-759-238-7685; E-mail: Limingyi168@126.com

Rec date: Oct 17, 2014, Acc date: Nov 21, 2014, Pub date: Nov 24, 2014

Copyright: @ 2014 Wen J, et al. This is an open-access article distributed under the terms of the Creative Commons Attribution License, which permits unrestricted use, distribution, and reproduction in any medium, provided the original author and source are credited.

\section{Abstract}

Aim: Previous studies have suggested Glypican-3 (GPC3) could be a valuable diagnostic marker for hepatocellular carcinoma. This study examined the effects of overexpression of GPC3 on Huh-7 hepatoma cells.

Methods: We constructed a recombinant plasmid vector pcDNA3.1 (+)-GPC3 for GPC3 overexpression studies in Huh-7 cells. RT-PCR and Western blotting were used to confirm GPC3 gene expression. Cell proliferation was evaluated by 5 -ethynyl-2-deoxyuridine (EdU) incorporation assay. Cell cycle progression and apoptosis were determined by flow cytometry using propidium iodide (PI) and Annexin V-FITC/PI staining, respectively. Cell migration and invasion were examined by Boyden Transewll and Matrigel assays.

Results: GPC3 overexpression effectively inhibited proliferation, induced cell cycle arrest at $S$ phase and increased apoptosis in Huh-7 cells. Furthermore, GPC3 overexpression significantly inhibited the migration and invasion ability of Huh-7 cells.

Conclusion: Our results demonstrate that GPC3 could be a new therapeutic target for hepatocellular carcinoma.

Keywords: Glypican-3; Hepatocellular carcinoma; Apoptosis; Invasion; Migration; Gene expression

\section{Introduction}

Hepatocellular carcinoma is the third leading cause of cancerrelated death in the world [1]. The outcome of patients with hepatocellular carcinoma is very poor with 5 -year survival rate is less than $10-15 \%[2,3]$. Several clinic pathological features, such as, poorly differentiated phenotype and portal venous invasion, have suggested to contribute to the poor prognosis in hepatocellular carcinoma patients. The underlying molecular mechanisms of the development of hepatocellular carcinoma remains elusive.

Glypican-3 (GPC3) is a member of the protein glycan family with a tissue-specific expression [4]. They are released from cell surface and functional to regulate the cell signaling of migration, proliferation and cell survival $[5,6]$. Previous studies have suggested that GPC3 is a valuable diagnostic biomarker for hepatocellular carcinoma $[7,8]$. Glypicans regulate several signaling pathways such as Wnts, hedgehogs, fibroblast growth factors which could exert stimulatory or inhibitory effects on cells. In cells predominately controlled by hedgehogs signaling, GPC3 inhibits cell proliferation, whereas in cell predominately controlled by Wnt signaling pathway, GPC3 stimulates cell proliferation [9-11]. GPC-3 have shown to be overexpressed in hepatocellular carcinoma [12]. Silencing GPC3 in hepatocellular carcinoma cells inhibited cell proliferation and increased cell apoptosis. Moreover, another study shows that suppression of GPC3 inhibits cell proliferation and cell cycle progression in HepG2 cells but no significant effect in the Huh-7 cells [9]. However, the potential effect of overexpression of GPC3 in hepatocellular carcinoma remains unclear.

In this study, we overexpressed GPC3 in Huh-7 cells by using the recombinant plasmid pcDNA3.1 (+)-GPC3 to analyze the effects of GPC3 overexpression on hepatocellular carcinoma.

\section{Materials and Methods}

\section{Huh-7 cell culture}

Human hepatocellular carcinoma Huh-7cells were purchased from Japanese Collection of Research Bioresources (JCRB) Cell Bank (Japan), and were cultured in complete Dulbecco's modified Eagle's medium (DMEM) (Invitrogen, Carlsbad, CA) supplemented with 10\% fetal bovine serum (FBS), 100 units $/ \mathrm{ml}$ penicillin, $100 \mathrm{mg} / \mathrm{ml}$ streptomycin, and $2 \mathrm{mM} \mathrm{L}$-glutamine (Invitrogen, Carlsbad, CA).

\section{Construction of plasmid pcDNA3.1 (+)-GPC3}

A GPC3-expressing plasmid [pcDNA3.1 (+)-GPC3] was prepared by using standard recombinant DNA methods [13]. Briefly, full-length 
GPC3 cDNA (GenBank: NM_004484.3) was cloned by reverse transcriptase polymerase chain reaction (RT-PCR). The forward primer GGGGTACCGCCACCATGGCCGGGACCGTGCGCAC-3') and the reverse primer (5'CCGGAATTCTCAGTGCACCAGGAAGAAGAAGCACACCA-3') with KpnI and EcoRI restriction sites (underlined bases) were used. The PCR amplification protocol for GPC3 was: an initial cycle of denaturation at $98^{\circ} \mathrm{C}$ for $2 \mathrm{~min}$, followed by 32 cycles of $98^{\circ} \mathrm{C}$ for 15 sec, $68^{\circ} \mathrm{C}$ for $90 \mathrm{sec}, 72^{\circ} \mathrm{C}$ for $40 \mathrm{sec}$ and one final cycle at $72^{\circ} \mathrm{C}$ for 5 $\mathrm{min}$. The PCR products of GPC3 (1743 bp) were electrophoresed on a $1.2 \%(\mathrm{~W} / \mathrm{V})$ agarose gel, and purified using the DNA purification kit (Takara, Japan). Then, the purified DNA fragment coding GPC3 sequence was cloned into the plasmid pcDNA3.1 (+) to obtain the plasmid [pcDNA3.1 (+)-GPC3], which was transformed into DH5a E.coli. inoculated in LB medium supplemented with $50 \mu \mathrm{g} / \mathrm{mL}$ ampicillin. The proper insert was confirmed by sequencing (Sangon Biotech, China). The plasmid was extracted using plasmid preparation kit (Qiagen, Germany) and purified using plasmid purification kit (Qiagen, Germany) according to the manufacturer's instruction.

\section{Transfection of pcDNA3.1 (+)-GPC3 into Huh-7 cells}

Huh-7 cells were transfected with the plasmid [pcDNA3.1 (+)GPC3] by using Lipofectamine 2000 (Invitrogen, Camarillo, USA) according to the manufacturer's instruction. GPC3 transfected Huh-7 cells were defined as Huh-7-GPC3 cells. Huh-7 cells transfected with blank plasmid pcDNA3.1 (+) were defined as mock-transfected cells, serving as a negative control (NC). The Huh-7 cells without transfection were defined as (blank) control cells. After $72 \mathrm{hr}$ transfection, the Huh-7 cells were used for various experiments.

\section{Real time RT-PCR analysis of GPC3 expression}

Real-time PCR was carried out on ABI 7900HT real-time PCR system 7900 (USA) using the PrimeScrip RT-PCR Kit (Takara, Japan) as previously reported [13]. Briefly, after $48 \mathrm{~h}$ of transfection, the total RNAs were extracted from control, negative control and Huh-7-PGC cells by using the Trizol reagent (Life Technologies, USA) according to the manufacturer's instruction. Then the RNAs were converted into cDNA using specific primers (forward, 5'AGAAACCTTATCCAGCCGAAGAA-3'; reverse, 5'TGGGTCCAACTACTAAGCT-3') and reverse transcription kit. GAPDH was used as an internal control. The relative gene expression was determined by using the $2-\Delta \Delta \mathrm{Ct}$ method. Experiment was repeated for three times.

\section{Proliferation assay of Huh-7 cells}

The Huh-7 cell proliferation was evaluated by using 5-ethynyl-2deoxyuridine (EdU) incorporation assay [14]. Briefly, after $72 \mathrm{hr}$ of transfection, cells were cultured in fresh complete culture medium (DMEM supplemented with 10\% fetal bovine serum (FBS) for $12 \mathrm{hr}$, followed by incubation with medium supplemented with $50 \mathrm{mM}$ EdU (1:1000) (Ribobio, Guangzhou, China) for $2 \mathrm{hr}$. Then, cells were fixed for $15 \mathrm{~min}$ at room temperature (RT), permeabilized with $0.5 \%$ Triton $\mathrm{X}-100$ in PBS for $20 \mathrm{~min}$, and incubated with apollo ${ }^{\bullet}$ fluorescent dye (Invitrogen, Carlsbad, CA) for $30 \mathrm{~min}$ at RT in the dark. 4', 6Diamidino-2- Phenylindole (DAPI) (Invitrogen, Carlsbad, CA) was used to counterstain the nucleus. Images were taken under a fluorescent microscope (Olympus, Japan)at three random fields. The percentage of EdU-positive cells was calculated as: EdU+ cells (\%) =
EdU+ cells / DAPI+ cells x 100\%. The experiment was performed for three times.

\section{Cell cycle and apoptosis analyses of Huh-7 cells}

Cell cycle progression of Huh-7 cells was determined by flow cytometry using propidium iodide (PI) [15]. Briefly, after $72 \mathrm{hr}$ of transfection, Huh-7 cells were trypsinized, fixed with cold $75 \%$ ethanol for $1 \mathrm{hr}$ and centrifuged. Then the cell pellet was resuspended and incubated with PI $(50 \mu \mathrm{g} / \mathrm{ml}$; Beyotime, China) containing RNaseA $(0.1 \mathrm{mg} / \mathrm{ml})$ in PBS for $30 \mathrm{~min}$ at RT in the dark. Sample was analyzed using a FACS can flow cytometer with Cell Quest software (Becton Dickinson, NJ, USA).

The apoptosis assay of Huh-7 cells was conducted by using Annexin V-FITC/PI apoptosis detection kit as previously described [16]. Briefly, after $72 \mathrm{hr}$ of transfection, Huh-7 cells were washed, incubated with Annexin V-FITC and PI staining solution (Becton Dickinson, USA) for $20 \mathrm{~min}$ at RT in the dark and then analyzed by flow cytometer. All experiments were performed for three times.

\section{Migration and invasion assays of Huh-7 cells}

The migration and invasion assays of Huh-7 cells was carried out by using Boyden chamber as previously described [17]. For cell invasion assay, the porous membrane of the top insert $(8.0 \mu \mathrm{m}$ pore size, BD Biosciences) was coated with matrigel ( $40 \mu \mathrm{l}$, BD Bioscience, USA) for $2-3 \mathrm{~h}$ at $37^{\circ} \mathrm{C}$. After $72 \mathrm{~h}$ of transfection, Huh-7 cells $(100 \mu \mathrm{l}, 1 \times 105 /$ well of a 24-well plate) were replaced with fresh serum-free DMEM and seeded on to the top insert or matrigel-coated top insert. Then, DMEM supplemented 10\% FBS $(600 \mu \mathrm{l})$ was added into the bottom well. After $24 \mathrm{~h}$ incubation at $37^{\circ} \mathrm{C}$, cells migrated through the porous membrane to bottom wells were fixed in $75 \%$ ethanol for $15 \mathrm{~min}$, stained with crystal violet solution (Sigma-Aldrich, USA), and cells invaded through matrigel and membrane to bottom well were directly counted under an inverted microscope, respectively. All experiments were repeated for three times.

\section{Western blot analysis of GPC3 expression}

After $72 \mathrm{hr}$ transfection, proteins were collected from different groups by using lysis buffer as previously described [13]. The protein lysates were then be electrophoresed through SDS-PAGE gel and transferred onto PVDF membranes. The membranes were blocked and probed with primary antibodies against GPC3 (Santa cruz, USA) or GAPDH (Santa cruz, USA) followed by incubation with HRPconjugated IgG. Blots were then developed with enhanced chemiluminescence developing solutions and quantified under Image J software.

\section{Statistical Analysis}

Data were presented as the mean \pm SD (standard deviation). Comparisons among multiple groups were analyzed by ANOVA using the SPSS 17.0 software and the comparison between two groups was analyzed by Student's t-test. $\mathrm{P}<0.05$ was considered statistically significant. 
Citation: Wen J, Wen X, Wang J, Shu Y, Qiu Z, et al. (2014) Anti-cancer Effects of Glypican-3 on Huh-7 Hepatocellular Carcinoma Cells. J Cell

Page 3 of 6

\section{Results}

mRNA and protein expression of GPC 3 in Huh-7 cells were increased after plasmid pcDNA3.1 (+)-GPC3 transfection

The real time RT-PCR results showed that the expression level of GPC3 in the Huh-7 cells transfected with GPC3 was significantly higher than that in control or mock groups (Figure 1A) $(\mathrm{P}<0.01$, control or mock Vs. Huh-7-GPC3). There is no significant difference between control and mock groups ( $\mathrm{P}>0.05$, control vs. mock). The protein expression level of GPC3 was increased in Huh-7-GPC3 cells as revealed by western blot analysis (Figure $1 \mathrm{~B}$ and $1 \mathrm{C})(\mathrm{P}<0.05$, control or mock Vs. Huh-7-GPC3). Similarly, there is no difference of GPC3 protein expression between control and mock groups $(\mathrm{P}>0.05$, control Vs. mock).

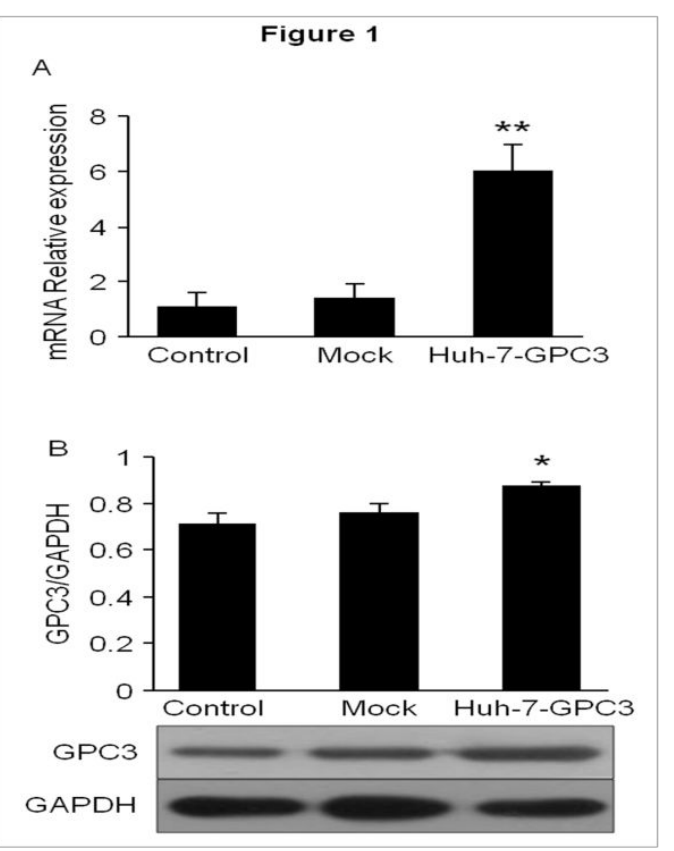

Figure 1: GPC3 overexpression in Huh-7 cells after GPC3 transfection. A: Relative expression of GPC3 mRNA in Huh-7 cells transfected with cDNA3.1 (+)-GPC3, blank plasmid (mock), or control. B: Representative western blot bands of GPC3 protein expression in in Huh-7 cells transfected with cDNA3.1 (+)-GPC3, blank plasmid (mock), or control. GAPDH used as a loading control. C: Summarized data of GPC3 protein expression in three groups. Data was expressed as mean $\pm \mathrm{SD}, \mathrm{n}=3$ /group, ${ }^{\star} \mathrm{P}<0.05$, ${ }^{*} \mathrm{P}<0.01$, versus control or mock.

\section{Overexpression of GPC3 inhibited the proliferation of Huh-7 cells}

The effect of GPC3 overexpression on the proliferation of Huh-7 cells was evaluated by EdU incorporation assay. As shown in Figure 2, the percentage of EdU-positive cells was significantly decreased in Huh-7-GPC3 group as compared to that in control and mock groups $(\mathrm{P}<0.05,90.1 \pm 5.9 \%, 91.0 \pm 2.5 \%$, and $81.06 \pm 3.6 \%$ for control, mock and Huh-7-GPC3, respectively; control or mock Vs. Huh-7-GPC3). And there was no significant difference of EdU-positive cells between control and mock groups ( $\mathrm{P}>0.05$, control Vs. mock). These results indicated that overexpression of GPC 3 in Huh-7 cells could inhibit cell proliferation.

\section{Overexpression of GPC3 inhibited Huh-7 cell cycle progression}

As shown in Figure 3, the flow cytometric results showed that there was a significant increase of S phase Huh-7 cells in GPC3 transfection group $(\mathrm{P}<0.05$, control or mock Vs. Huh-7-GPC3). In addition, a concomitant increase of Huh-7 cells in sub G1 phase and reduction of Huh-7 cells in G2/M phase were observed in the GPC3 transfection group $(\mathrm{P}<0.05$, control or mock Vs. Huh-7-GPC3 ). And the proportion of cells at the G1 phase was not significantly changed.

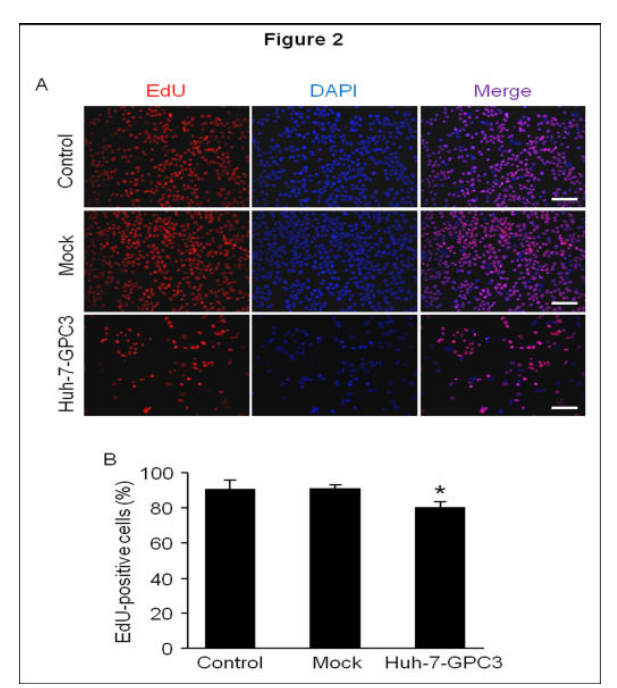

Figure 2: Effect of GPC3 overexpression on EdU incorporation into Huh-7 cells. A: Representative images of EdU incorporation and DAPI staining in Huh-7 cells transfected with cDNA3.1 (+)-GPC3, blank plasmid (mock), or control. Scale bar: $100 \mu \mathrm{m}$. B: Summarized data of Edu expression in the three groups. Data was expressed as mean $\pm \mathrm{SD}, \mathrm{n}=3$ /group. ${ }^{*} \mathrm{P}<0.05$, versus control or mock.

\section{Overexpression of GPC3 increased apoptosis of Huh-7 cells}

To investigate the potential effect of GPC3 overexpression on cellular apoptosis, the treated cells were stained with annexin VFITC/PI and analyzed by flow cytometry. We found that there were higher percentages of both early stage apoptotic cells and late stage apoptosis and necrotic cells in the Huh-7-GPC3 groups when compared to those in control or mock groups $(\mathrm{P}<0.05$, control or mock Vs. Huh-7-GPC3; Figure 4A and 4B).

\section{Overexpression of GPC3 decreased the migration and invasion abilities of Huh-7 cells}

Our results showed that Huh-7 cell migration ability was significantly suppressed in Huh-7-GPC3 cells when compared to that in control or mock groups $(\mathrm{P}<0.01$, control or mock Vs. Huh-7-GPC3; Figure 5A). The percentage of cells passed through the membrane of the inserters to the bottom wells was reduced from $47.3 \pm 7.7 \%$ 
(control group) or $40.9 \pm 10.1 \%$ (mock group) to $14.0 \pm 5.2 \%$ (Huh-7GPC3 group). These results supported that GPC3 overexpression could effectively inhibit cell migration.

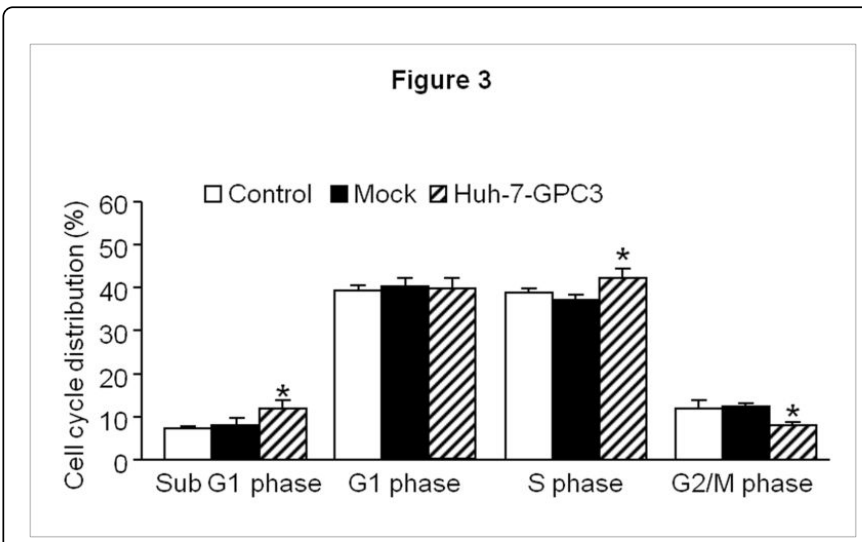

Figure 3: Effects of GPC3 overexpression on cell cycle of Huh-7 cells. Summarized data of Huh-7 cells distributed in the subG1, G1, G2/M and S phase in control, mock and GPC3 overexpression groups. Data was expressed as mean $\pm \mathrm{SD}, \mathrm{n}=3$ /group. ${ }^{\star} \mathrm{P}<0.05$, versus control or mock.
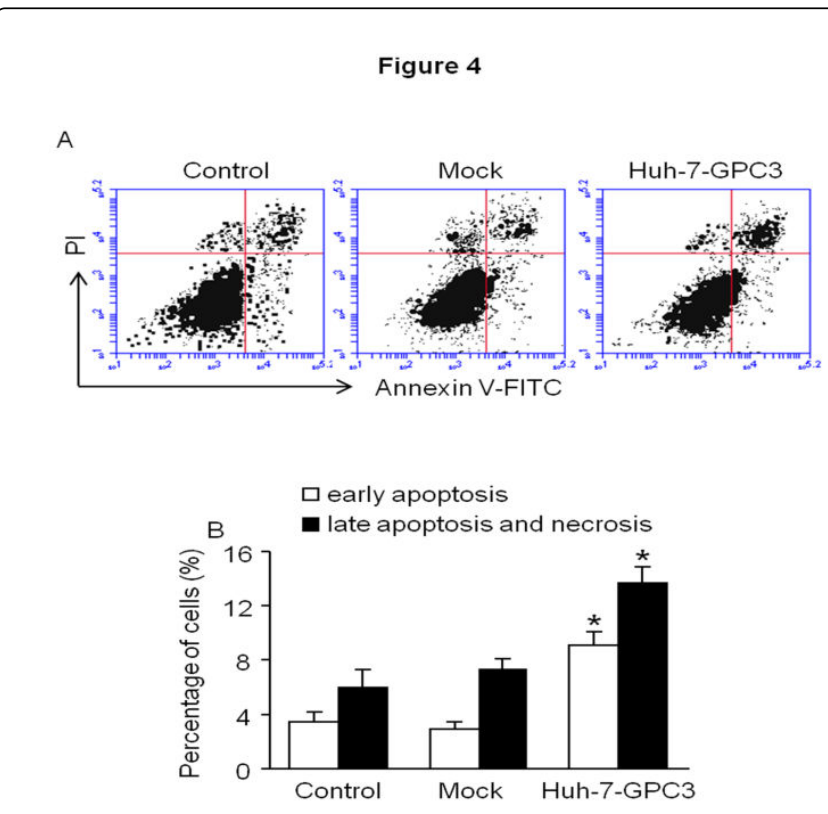

Figure 4: Effects of GPC3 overexpression on apoptosis of Huh-7 cells. A: Representative flow cytometric plots showing the distribution of Huh-7 cells in the three group. Cells in the lower right quadrants were defined early apoptotic cells. Cells in the upright quadrants were defined as late apoptosis cells. B. Summarized data of Huh- 7 cell apoptosis in the three groups. Data was expressed as mean $\pm \mathrm{SD}, \mathrm{n}=3$ /group. ${ }^{\star} \mathrm{P}<0.05$, versus control or mock.

The results of invasion assay showed that GPC3 overexpression significantly lowered the invasion activity of Huh-7 cells as compared to those in control or mock groups $(\mathrm{P}<0.05$, control or mock Vs.
Huh-7-GPC3; Figure 5B). The percentage of cells invaded through the matrigel and membrane to the bottom wells was apparently decreased from $7.9 \pm 1.5 \%$ (control group) or $10.6 \pm 4.2 \%$ (mock group) to $4.9 \pm$ $1.2 \%$ (Huh-7-GPC3 group). These results showed that GPC3 overexpression could effectively suppress GPC3 cell invasion.

\section{Discussion}

In the present study, we found that overexpression of GPC3 in Huh-7 cells can inhibit cell proliferation, induce apoptosis, arrest cell cycle progression at the $S$ phase, and suppress Huh-7 cell migration and invasion.

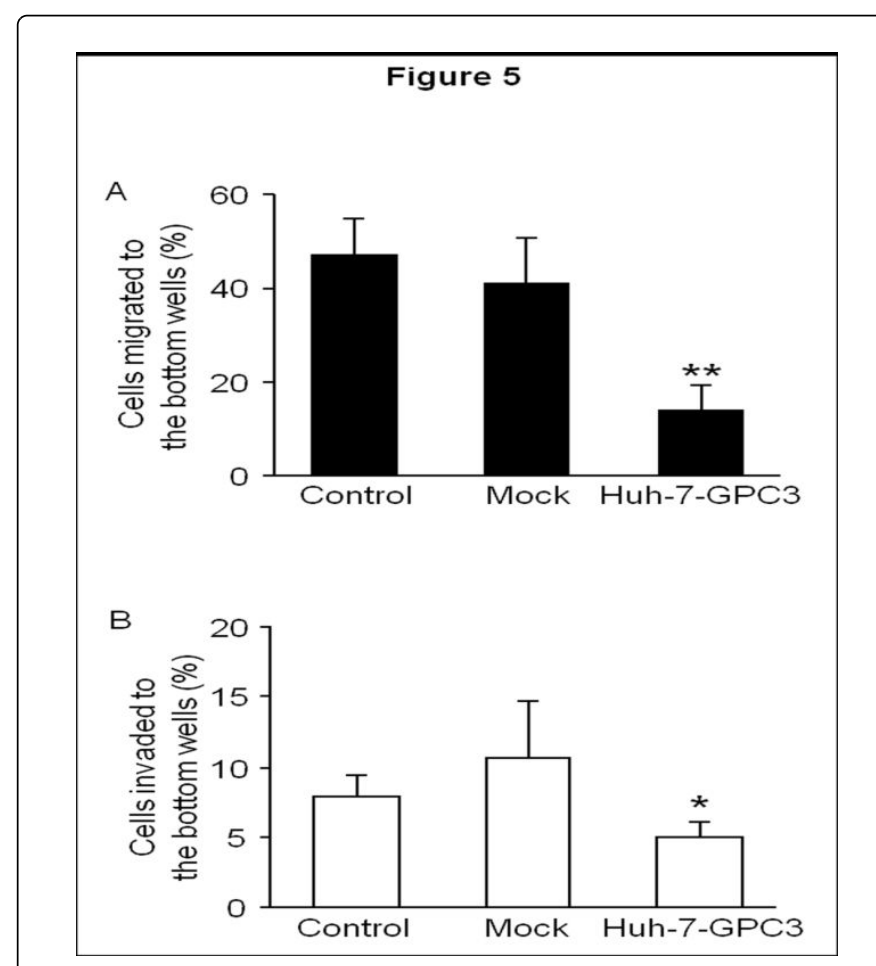

Figure 5: Effects of GPC3 overexpression on the migration and invasion abilities of Huh-7 cells. A: Summarized data of Huh-7 cell migrated through the polycarbonate membrane with $8.0 \mu \mathrm{M}$ pore size to the bottom wells in the control, mock and Huh-7-GPC3 groups. B: Summarized data of Huh-7 cell invaded through the matrigel-coated membrane to the bottom wells in the control, mock and Huh-7-GPC3 groups. Data was expressed as mean \pm SD, $\mathrm{n}=3$ /group. ${ }^{\star} \mathrm{P}<0.05,{ }^{* *} \mathrm{P}<0.01$, versus control or mock.

GPC3 is a member of the glypican family that plays an important role in modulating cell growth, migration, invasion and cell cycle progression $[18,19]$. The protein expression of GPC3 is up-regulated in hepatocellular carcinoma [12]. Interestingly, we found that GPC3 overexpression could effectively inhibiting cell proliferation as revealed by using EdU staining in the Huh-7 cells. We speculate that the inhibition of cell proliferation resulted from cell cycle arrest, because cell cycle checkpoints are critical intersections for cell growth. In order to validate our hypothesis regarding to the suppression of cell proliferation is associated with cell cycle arrest, we determined Huh-7 cell cycle progression by flow cytometry. Our results revealed that overexpression of GPC3 arrested Huh-7 cells at S phase, decreased the percentage of Huh-7 cells at G2/M phase, and concurrently increased 
cell apoptosis and necrosis at sub G1 phase. Our cell proliferation data are in line with the cell cycle results. For proliferation assay, the EdU positive cells were measured after an additional $12 \mathrm{hrs}$ culture following GPC3 overexpression. Whereas, for cell cycle assay, PI staining was performed immediately following GPC3 overexpression. The EdU experiment revealed a decrease in the percentage of $S$ phase cells, suggesting the inhibitive effect of GPC3 on cell proliferation. For the PI experiment, we observed an increase in the percentage of $S$ phase cells. This could be interpreted by $S$ phase cell accumulation because we found that there was a decrease in percentage of $G 2 / M$ phase cells, indicating that GPC3 prevents cells enter into G2/M phase. These data generated from different experiment protocols together suggest that the growth-inhibitory effects of GPC3 overexpression could result from changes in the cell cycle.

Several previous studies have suggested the involvement of GPC3 in hepatocellular carcinoma [12,20,21]. Of note, silencing GPC3 in hepatocellular carcinoma cells has been shown to inhibit cell proliferation and increase cell apoptosis [21]. Moreover, a study has shown that suppression of GPC3 inhibits cell proliferation and cell cycle progression in HepG2 cells but no significant effect in the Huh-7 cells [9]. Such a discrepancy could exist because of different cell lines as well as experimental conditions applied for the studies. Nevertheless, the more underlying mechanisms require further investigation.

Apoptosis induction is considered as a very useful approach for cancer therapy. Many studies have indicated that GPC3 plays an important role in regulating cell survival $[18,19]$. A previous report showed that murine mammary tumor LM3 cells overexpressing GPC3 were much more sensitive to apoptosis induction [22]. Consistently, we observed that Huh-7 cells transfected with GPC3 plasmid had a increased percentage of apoptotic rate in this study.

It is well-known that cell migration and invasion play a crucial role in cancer [23]. And proteolytical disruption of basement membrane is a key step involved in the migration and invasion processes. In the present study, we examined the migration and invasion abilities of the Huh-7 cells trasnfected with GPC3 plasmid. Our results showed that overexpression of GPC3 in Huh-7 cells significantly inhibited cell migration and invasion. Further studies will be performed to clarify the mechanisms underlying the biologic effects of GPC3 on Huh-7 cells.

In conclusion, our results demonstrate that the overexpression of GPC3 in Huh-7 cells inhibits cell proliferation, induces apoptosis associated with arresting cell cycle progression at the $\mathrm{S}$ phase, and suppresses cell migration and invasion. These data indicate the diagnostic and therapeutic potential of GPC3 in hepatocellular carcinoma patients.

\section{Acknowledgements}

This work was supported by the Scientific Project Foundation of Guangdong Province, China (20101700501and 2011B031800249).

\section{References}

1. Darvesh AS, Aggarwal BB, Bishayee A (2012) Curcumin and liver cancer: a review. Curr Pharm Biotechnol 13: 218-228.

2. Kawano Y, Sasaki A, Kai S, Endo Y, Iwaki K, Uchida H, Shibata K, Ohta M, Kitano S (2008) Short- and long-term outcomes after hepatic resection for hepatocellular carcinoma with concomitant esophageal varices in patients with cirrhosis. Ann Surg Oncol 15: 1670-1676.
3. Zhang L, Liu H, Sun L, Li N, Ding H, Zheng J (2012) Glypican-3 as a potential differential diagnosis marker for hepatocellular carcinoma: a tissue microarray-based study. Acta Histochem 114: 547-552.

4. Li M, Choo B, Wong ZM, Filmus J, Buick RN (1997) Expression of OCI-5/glypican 3 during intestinal morphogenesis: regulation by cell shape in intestinal epithelial cells. Exp Cell Res 235: 3-12.

5. Pilia G, Hughes-Benzie RM, MacKenzie A, Baybayan P, Chen EY, et al. (1996) Mutations in GPC3, a glypican gene, cause the Simpson-GolabiBehmel overgrowth syndrome. Nat Genet 12: 241-247.

6. Cano-Gauci DF, Song HH, Yang H, McKerlie C, Choo B, et al. (1999) Glypican-3-deficient mice exhibit developmental overgrowth and some of the abnormalities typical of Simpson-Golabi-Behmel syndrome. J Cell Biol 146: 255-264.

7. Kandil DH, Cooper K (2009) Glypican-3: a novel diagnostic marker for hepatocellular carcinoma and more. Adv Anat Pathol 16: 125-129.

8. Suzuki M, Sugimoto K, Tanaka J, Tameda M, Inagaki Y, et al. (2010) Upregulation of glypican-3 in human hepatocellular carcinoma. Anticancer Res 30: 5055-5061.

9. Sun CK, Chua MS, He J, So SK (2011) Suppression of glypican 3 inhibits growth of hepatocellular carcinoma cells through up-regulation of TGFß2. Neoplasia 13: 735-747.

10. Filmus J, Capurro M, Rast J (2008) Glypicans. Genome Biol 9: 224.

11. Capurro MI, Xiang YY, Lobe C, Filmus J (2005) Glypican-3 promotes the growth of hepatocellular carcinoma by stimulating canonical Wnt signaling. Cancer Res 65: 6245-6254.

12. Sung YK, Hwang SY, Park MK, Farooq M, Han IS, et al. (2003) Glypican-3 is overexpressed in human hepatocellular carcinoma. Cancer Sci 94: 259-262.

13. Cheng W, Tseng CJ, Lin TT, Cheng I, Pan HW, et al. (2008) Glypican-3mediated oncogenesis involves the Insulin-like growth factor-signaling pathway. Carcinogenesis 29: 1319-1326.

14. Yu Y, Arora A, Min W, Roifman CM, Grunebaum E (2009) EdU incorporation is an alternative non-radioactive assay to [(3) H]thymidine uptake for in vitro measurement of mice T-cell proliferations. J Immunol Methods 350: 29-35.

15. Rahabi-Layachi H, Ourouda R, Boullier A, Massy ZA, Amant C (2014) Distinct effects of inorganic phosphate on cell cycle and apoptosis in human vascular smooth muscle cells. J Cell Physiol .

16. Liu S, Li Y, Chen W, Zheng P, Liu T, et al. (2012) Silencing glypican-3 expression induces apoptosis in human hepatocellular carcinoma cells. BiochemBiophys Res Commun 419: 656-661.

17. Zeng G, Cai S, Liu Y, Wu GJ (2012) METCAM/MUC18 augments migration, invasion, and tumorigenicity of human breast cancer SK-BR-3 cells. Gene 492: 229-238.

18. Sakurai M, Shibata K, Umezu T, Kajiyama H, Yamamoto E, et al. (2010) Growth-suppressing function of glypican-3 (GPC3) via insulin like growth factor II (IGF-II) signaling pathway in ovarian clear cell carcinoma cells. Gynecol Oncol 119: 332-336.

19. Yu D, Dong Z, Yao M, Wu W, Yan M, et al. (2013) Targeted glypican-3 gene transcription inhibited the proliferation of human hepatoma cells by specific short hairpin RNA. Tumour Biol 34: 661-668.

20. Gao H, Li K, Tu H, Pan X, Jiang H, et al. (2014) Development of T Cells Redirected to Glypican-3 for the Treatment of Hepatocellular Carcinoma. Clin Cancer Res . 1078-0432.CCR-14-1170.

21. Qi XH, Wu D, Cui HX, Ma N, Su J, et al. (2014) Silencing of the glypican-3 gene affects the biological behavior of human hepatocellular carcinoma cells. Mol Med Rep 10: 3177-3184

22. Peters MG, Farías E, Colombo L, Filmus J, Puricelli L, et al. (2003) Inhibition of invasion and metastasis by glypican-3 in a syngeneic breast cancer model. Breast Cancer Res Treat 80: 221-232.

23. Li L, Chen P, Ling Y, Song X, Lu Z, et al. (2011) Inhibitory effects of GLV9 on the invasion of human breast carcinoma cells by downregulating the expression and activity of matrix metalloproteinase-2/9. Eur J Pharm Sci 43: 393-399. 
Citation: Wen J, Wen X, Wang J, Shu Y, Qiu Z, et al. (2014) Anti-cancer Effects of Glypican-3 on Huh-7 Hepatocellular Carcinoma Cells. J Cell Sci Ther 5: 1000186. doi:10.4172/2157-7013.1000186 